\title{
Chondroitin sulfate and hydroxyapatite from Prionace glauca shark jaw: Physicochemical and structural characterization
}

\author{
Miriam López-Álvarez ${ }^{\text {a }}$, Pío González ${ }^{\text {a }}$, Julia Serra ${ }^{\mathrm{a}, *}$, Javier Fraguas ${ }^{\mathrm{b}}$, Jesús Valcarcel ${ }^{\mathrm{b}}$, José Antonio \\ Vázquez ${ }^{\mathrm{b}}$ \\ ${ }^{a}$ New Materials Group, Department of Applied Physics, University of Vigo, IISGS, MTI, Campus \\ Lagoas-Marcosende, Vigo 36310, Spain \\ ${ }^{\mathrm{b}}$ Group of Recycling and Valorisation of Waste Materials (REVAL), Marine Research Institute (IIM- \\ CSIC), r/Eduardo Cabello, 6, Vigo 36208, Galicia, Spain
}

\begin{abstract}
In the present work, the potential of the Prionace glauca jaw as a source of both chondroitin sulfate and bioapatite is explored. The sandwich-type structure in cross section of the jaw based on alternate layers with prevalence in organic tissue or mineralized is shown and these bands respectively confirmed as CS or hydroxyapatite enriched zones. As result of this, an optimized process in sequential steps for the recovery of both biomaterials and their purification process is proposed, by combining enzymatic proteolysis, chemical precipitation and separation using ultrafiltration membrane for CS production together with controlled thermal treatment for hydroxyapatite obtaining. The purified CS was characterized by Gel Permeation Chromatography, Nuclear Magnetic Resonance and Strong Anion Exchange Chromatography, revealing a polymeric material with a molecular weight of $67 \mathrm{kDa}$, and prevalent $6 \mathrm{~S}-$ GalNAc sulfation $(68 \%)$, followed by 4 S-GalNAc (13\%), a significant proportion of disulfated disaccharides (12\%) and only $7 \%$ of non-sulfated units. In the case of the bioapatite a purified biphasic 60:40 porous calcium phosphate of hydroxyapatite: whitlockite/ $\beta$-TCP was confirmed. Hydroxyapatite as major component $(85 \%)$ was also obtained for jaws directly subjected to the thermal treatment. This proved the influence of the enzymatic hydrolysis and centrifugation on the composition of the mineral fraction.
\end{abstract}

\section{Introduction}

The marine environment applications [1,2,3]. Some of these compounds may occur in rare and unexploited organisms, but many marine biomaterials originate from commonly fished species. This is the case of blue shark (Prionace glauca), a wideranging oceanic chondricthyan dispersed across temperate and tropical waters. This 
species represents a relatively abundant source of fish by-products, mostly heads and skeletons, amenable to be processed to obtain valuable biomaterials [4].

Apatites and, in particular, hydroxyapatite (HA) is a bioactive bioceramic which belongs to the family of calcium phosphates and fits the ideal formula $\mathrm{Ca}_{10}\left(\mathrm{PO}_{4}\right)_{6}(\mathrm{OH})_{2}$. This basic composition enriched by groups and elements in trace concentrations, as $\mathrm{CO}_{3}{ }^{2-}, \mathrm{HPO}_{4}{ }^{2-}, \mathrm{Na}^{+}, \mathrm{Mg}^{2+}, \mathrm{Sr}^{2+}, \mathrm{K}^{+}, \mathrm{Cl}^{-}$and $\mathrm{F}^{-}$, constitute the mineral fraction of bone tissue. The rest of the tissue is formed by collagen with other proteins and water. This composition gives the bone tissue a great consistency, hardness, elasticity and resistance to compression [5,6,7]. Moreover, as a bioactive material, HA has the ability to induce its biological integration in living tissues, so that it interacts chemically with the organism, giving rise to a layer rich in phosphorus and calcium on its surface in the form of bioapatite [6,8]. It is, therefore, a property of great interest to promote the activity of bone tissue forming cells, since the presence of hydroxyapatite and the bioactivity generated activate the adhesion, proliferation and osteoblast activity of osteoblasts.

In recent years HA-based materials of biological origin as bone substitutes have attracted greater interest than those of synthetic origin, given that their behaviour is biologically more active compared with synthetic equivalents $[9,10,11,12,13]$. Moreover, in contrast to commercial synthetic HA the biological version (mainly bovine, porcine origin) is enriched, as in human bones, with essential elements (such as $\mathrm{Mg}^{2+}, \mathrm{K}^{+}, \mathrm{Na}^{+}$, etc.) that have specific roles of relevance in bone defect healing, and it has lower crystallinity with disordered nanostructures providing unique chemical and physical properties $[10,11,14]$. New biological sources are being investigated seeking to guarantee sustainability. One such approach is exploring the potential of the marine environment, especially discards from the fishing industry.

Chondroitin sulfate (CS) is a sulfated polysaccharide of the glycosaminoglycan family formed by alternating $\beta 1-3$ and $\beta 1-4$ glycosidic bonds between glucuronic acid (GlcA) and N-acetyl galactosamine (GalNAc). The basic building block of the polymer is the disaccharide thus formed, which can be sulfated at different positions on both rings. In animals, CS participates as regulator of functional proteins, either at the cell surface or in the extracellular matrix [15], being consequently involved in important processes such as viral infection, metastasis and neurite outgrowth [16]. As a result, CS has found 
applications as pharmaceutical [17] and nutraceutical [18], and is actively researched in tissue engineering [19]

The CS ability to interact with proteins appears to be influenced by charge density [20], mainly driven by sulfate groups [21]. In this regard, CS from cartilaginous fish and terrestrial sources can be considered different, as charge density is generally higher in fish CS. This is due to the presence of disulfated units in fish CS and a lower percentage of unsulfated units than in bovine and porcine CS. Although disaccharide composition varies considerably across fish species and also among tissues within the same species $[22,23]$, prevalent sulfation in CS from cartilaginous fish generally occurs in position 6 of GalNAc, while position 4 is the most common in terrestrial sources [24].

Bioapatite and CS originate from distinct shark tissues. CS is a fundamental constituent of cartilage and is mainly extracted from shark heads [25], while bioapatite occurs in hard tissues such as vertebrae and teeth. The latter are especially valuable, as dentine and enameloid present in teeth are promising biomaterials for bone regeneration $[7,26,27]$. Their obtention implies, as a first step, removal of the jaws from the head to subsequently extract the teeth. The process leaves the remaining jaw as a by-product, yet this material still holds potential for further valorization. With this aim, in the present work we characterize crude blue shark jaws to identify potential HA and CS as valorization products. Both biomaterials are isolated and purified, to the best of our knowledge, for the first time in shark jaws. The isolation is carried out following sustainability principles to minimize our impact in the marine environment. An optimized process in sequential steps is proposed by combining enzymatic proteolysis, chemical precipitation and membrane purification, together with controlled thermal treatment for hydroxyapatite purification. Enzymatic deproteinization was implemented in an environmental friendly method against corrosive alkali following operation at optima parameters previously defined for blue shark CS [4].

\section{Materials and Methods}

\subsection{Raw material preparation and chemical analysis}

Heads by-products of blue shark (Prionace glauca) were boiled for $2 \mathrm{~h}$ and jaws separated manually, the remaining muscle was used for the production of fish protein hydrolysates [28] and teeth were removed to produce calcium phosphates [5]. The clean jaws were used for structural and chemical characterization as described below. Further samples of jaws were milled and homogenized at $\sim 1-5 \mathrm{~mm}$ size using a grinder. 
Proximate composition of crude and dried jaws (generated in a laboratory oven at $60{ }^{\circ} \mathrm{C}$ for $24 \mathrm{~h}$ ) was assessed by determination of moisture, organic matter and ash content [29]. Fat concentration, total nitrogen and total protein as total nitrogen $\times 6.25$ were also determined in various cases [29]. Total carbohydrate content was estimated by subtracting protein, fat, ash and moisture from total sample weight. This value of carbohydrates was confirmed by total sugar determination [30]after exhaustive enzymatic proteolysis of cartilage. Samples from the different purification steps were analysed to quantify total soluble proteins (Pr) [31], and CS concentration as glucuronic acid [32] according to the mathematical modifications reported in [33]. CS purity index (Ip), defined as Ip $(\%)=\mathrm{CS} \times 100 /(\mathrm{CS}+\mathrm{Pr})$, was also calculated in all purification steps.

\subsection{Purification of biomolecule and biomaterial from blue shark jaws}

The procedure applied for the valorization of jaws, to recover and purify bioapatite and chondroitin sulfate, followed the previously steps optimized for head cartilages of blue shark [34], but with slight modifications for the present work. The optimized flow diagram is presented in Figure 1, where the route for the obtaining of only purified bioapatite, from the direct thermal processing of the crude jaw, has been also included (named as calcium phosphate 1, CaP1). Going into detail with the procedure, 250-300 $\mathrm{g}$ of milled jaws were mixed with $750-900 \mathrm{~mL}$ of water and the mixture was hydrolyzed, in a 2L-reactor, for $8 \mathrm{~h}$ with Alcalase 2.4L from Bacillus licheniformis (Novozyme Nordisk, Bagsvaerd, Denmark) at a concentration of $1 \%$ (v/w of initial substrate), $\mathrm{pH}$ 8.2, temperature of $56{ }^{\circ} \mathrm{C}$ and agitation of $200 \mathrm{rpm}$. After jaw digestion, the centrifugation (6000 g / $20 \mathrm{~min}$ ) of the hydrolysate led to a sediment, non-hydrolysable material (NHM), and a supernatant rich in proteins and chondroitin sulfate (CS) (enzyme hydrolysate (EH) in Figure 1). NHM was washed and filtered (using Whatman filter $\mathrm{N}^{\circ} 4$ ) and the obtained mineral material was thermally processed as described below to obtain the named $\mathrm{CaP} 2$. The supernatant $(\mathrm{EH})$ was treated with a hydroalcoholic-alkaline-saline solution $(0.54 \mathrm{M} \mathrm{NaOH}, 1.17$ volumes of EtOH and 2.5 $\mathrm{g} / \mathrm{L}$ of $\mathrm{NaCl}$ ) for $2 \mathrm{~h}$ for the selective precipitation of CS. The impure CS recovered after centrifugation (6000 g / $20 \mathrm{~min}$ ) was redissolved in water and neutralized with $6 \mathrm{M}$ $\mathrm{HCl}$. Then, CS was purified by ultrafiltration (UF) membrane of $30 \mathrm{kDa}$ employing a first step of concentration (by 2-folds) and a subsequent stage of diafiltration (DF), applying 5 diavolumes of distilled water for the elimination of low proteins and 
peptides. Finally, purified solutions of CS obtained from DF retentates were dried by lab oven at $60^{\circ} \mathrm{C}$ for $48 \mathrm{~h}$. This complete protocol was carried out in duplicate.

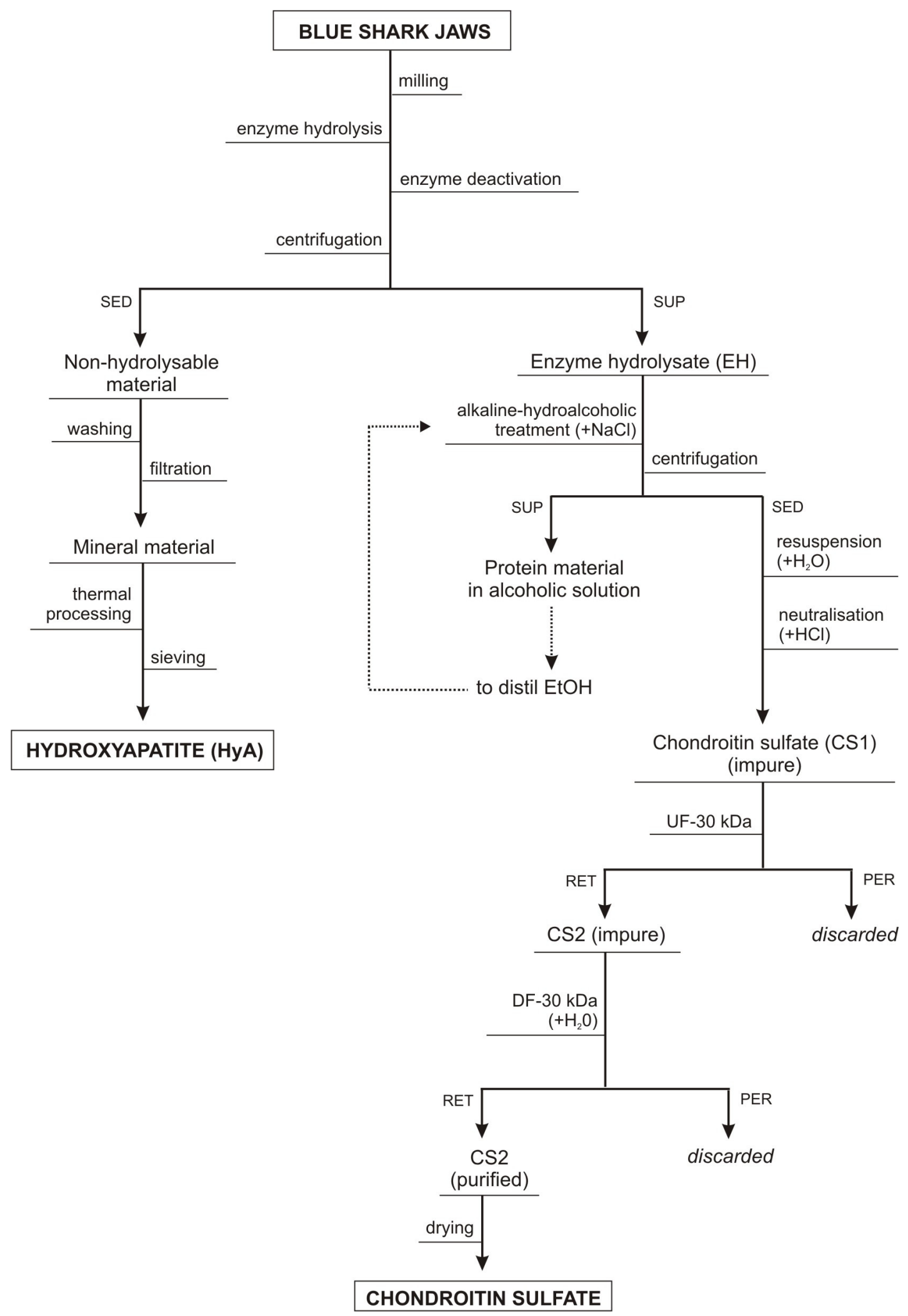

Figure 1. Flowchart of the valorization steps executed for the recovery and purification of valuable biomaterials from jaw of blue shark. SUP: supernatant, SED: sediment, RET: retentate and PER: permeate. 


\subsection{Structural and chemical characterization of shark jaws}

The crude mineral fraction obtained as a solid after subjecting the dried jaws to the enzyme hydrolysis combined with the separation by centrifugation (non-hydrolysable material $\mathrm{NHM}$ ) was calcined at $950{ }^{\circ} \mathrm{C}$ in a controlled thermal treatment for $12 \mathrm{~h}$ with heating ramp of $2{ }^{\circ} \mathrm{C} / \mathrm{min}$ and cooling ramp of $20^{\circ} \mathrm{C} / \mathrm{min}$. The same process was directly performed on dried jaws. Unprocessed samples of crude jaw in cross section, the ones obtained after direct thermal treatment $(\mathrm{CaP} 1)$ and the pyrolyzed powder from the NHM fraction (CaP2) were characterized in depth as follows: The morphology and elemental composition by scanning electron microscopy (SEM, JEOL JSM-6700F) and X-ray analysis by electron dispersive spectroscopy (EDS, Oxford Inca Energy 300). The evaluation of functional groups was performed by an FT-Raman B\&WTEK i-Raman$785 \mathrm{~S}$ instrument equipped with a BAC 100 Probe $(785 \mathrm{~nm})$ and structural measurements by X-Ray Diffraction (XRD) on a Siemens D-5000 Diffractometer.

\subsection{Molecular weight and sulfation of CS}

Molecular weight of CS was determined as previously described by gel permeation chromatography [35]. Briefly, $100 \mu \mathrm{l}$ of $\mathrm{CS}$ at $1 \mathrm{~g} / \mathrm{L}$ were separated with a set of Suprema columns (PSS, Germany) - $30 \AA, 100 \AA$ and Ultrahigh - eluted with $0.1 \mathrm{M}$ $\mathrm{NaN}_{3}$ : $0.01 \mathrm{M} \mathrm{NaH}_{2} \mathrm{PO}_{4}$, pH 6.6 on an Agilent 1260 equipped with refractive index and dual angle light scattering detectors. Refractive index increments (dn/dc) were calculated from the RI detector signal. Chemical composition was initially evaluated by ${ }^{1} \mathrm{H}$ NMR on a Bruker DPX 600 at $600 \mathrm{MHz}$ and $10^{\circ} \mathrm{C}$ at $1 \mathrm{~g} / \mathrm{L}$ in $\mathrm{D}_{2} \mathrm{O}$. Spectra were processed with MestReNova 10.0.2 software (Mestrelab Research, Spain). Detailed disaccharide composition was determined by strong anion exchange (SAX) chromatography as previously described [35]. Briefly, CS was digested with chondroitinase ABC (Prod. No. C2905, Sigma-Aldrich) at $0.2 \mathrm{U} \mathrm{mg}^{-1}$ of CS in $0.05 \mathrm{M}$ Tris- $\mathrm{HCl}: 0.15 \mathrm{M}$ sodium acetate $\mathrm{pH} 8$ at $37^{\circ} \mathrm{C}$ for $24 \mathrm{~h}$, the enzyme inactivated, samples centrifugated and the supernatant injected $(20 \mu \mathrm{L})$ onto an Agilent 1200 HPLC equipped with a Waters Spherisorb SAX column $(5 \mu \mathrm{m}, 4.6$ x $250 \mathrm{~mm})$. Elution was performed at $1.5 \mathrm{~mL} \mathrm{~min}^{-1}$ in isocratic mode from 0 to $5 \mathrm{~min}$ with $50 \mathrm{mM} \mathrm{NaCl} \mathrm{pH} 4$ and then in linear gradient from 5 to $25 \mathrm{~min}$, starting with $50 \mathrm{mM} \mathrm{NaCl} \mathrm{pH} 4$ and ending with $76 \% 50 \mathrm{mM} \mathrm{NaCl} \mathrm{pH} 4$ and $24 \% 1.2 \mathrm{M} \mathrm{NaCl} \mathrm{pH} \mathrm{4.} \mathrm{Disaccharides} \mathrm{were}$ detected at $232 \mathrm{~nm}$ and quantified by external calibration made with unsaturated standards (Grampenz, UK). 


\section{Results and Discussion}

\subsection{Shark jawbone: descriptive compositional analysis}

Crude blue shark jawbone appearance (including the teeth), once the soft tissue has been removed, is presented in Figure 2(a), together with a cut performed on the jaw structure (b). The last image (b) revealed the sandwich-type structure of the jaw in section formed by alternate layers of two different compositions, named at this work as ZONE1 (the darker) and as ZONE2 (the lighter ones) (b). At the same time it can also be observed as the inner structure of the jawbone acts also as a reservoir of dental tissue (white arrow).
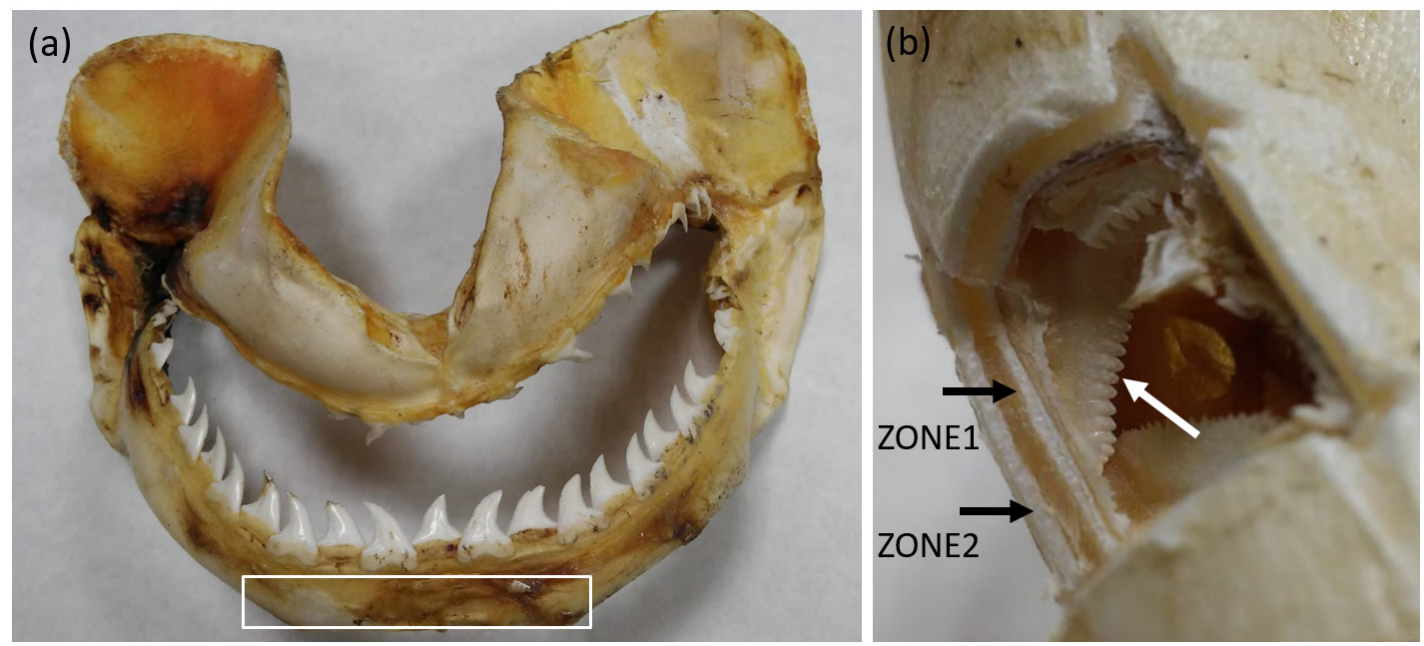

Figure 2. Optical image of entire crude jawbone of Prionace glauca (a) and a detail of the jaw in section (b)where a sandwich-type structure with alternate layers (ZONE1 and ZONE2) and the reservoir of dental tissue (white arrow) can be observed. The white square in (a) indicates the area where image (b) was taken.

These jawbone samples have been subjected to SEM and EDS analysis to elucidate the elemental composition of each layer (ZONE1, ZONE2). At Figure 3 the backscattered electrons (BSE) detector was used to obtain a micrograph of the jawbone cross section. Using this mode the obtained micrograph showed the variations in atomic number of the elements, with lighter tones for ZONE2 (heavier elements) and darker for ZONE 1. This qualitative indication of the different composition of the two layers (ZONE1, ZONE2) was confirmed with the elemental composition by EDS corresponding measurements (shown in Figure 3) with: a clear prevalence in mineralized composition for ZONE2 (measured on the whitest area) based in $\mathrm{Ca}$ and $\mathrm{P}$ (calcium phosphate), with presence of $\mathrm{C}$ of organic material and low relative intensity of $\mathrm{Na}$ and $\mathrm{Cl}$ from marine salts; in the 
case of ZONE1 the major composition is constituted by $\mathrm{C}$ with the presence in relevant relative intensity of $\mathrm{S}$, and a lower presence of $\mathrm{Ca}$ and $\mathrm{P}$ with, again, marine salts. In both ZONES the presence of $\mathrm{O}$ was detected (as it forms part of both organic and inorganic contributions) and $\mathrm{Mg}$ in a very lower proportion.

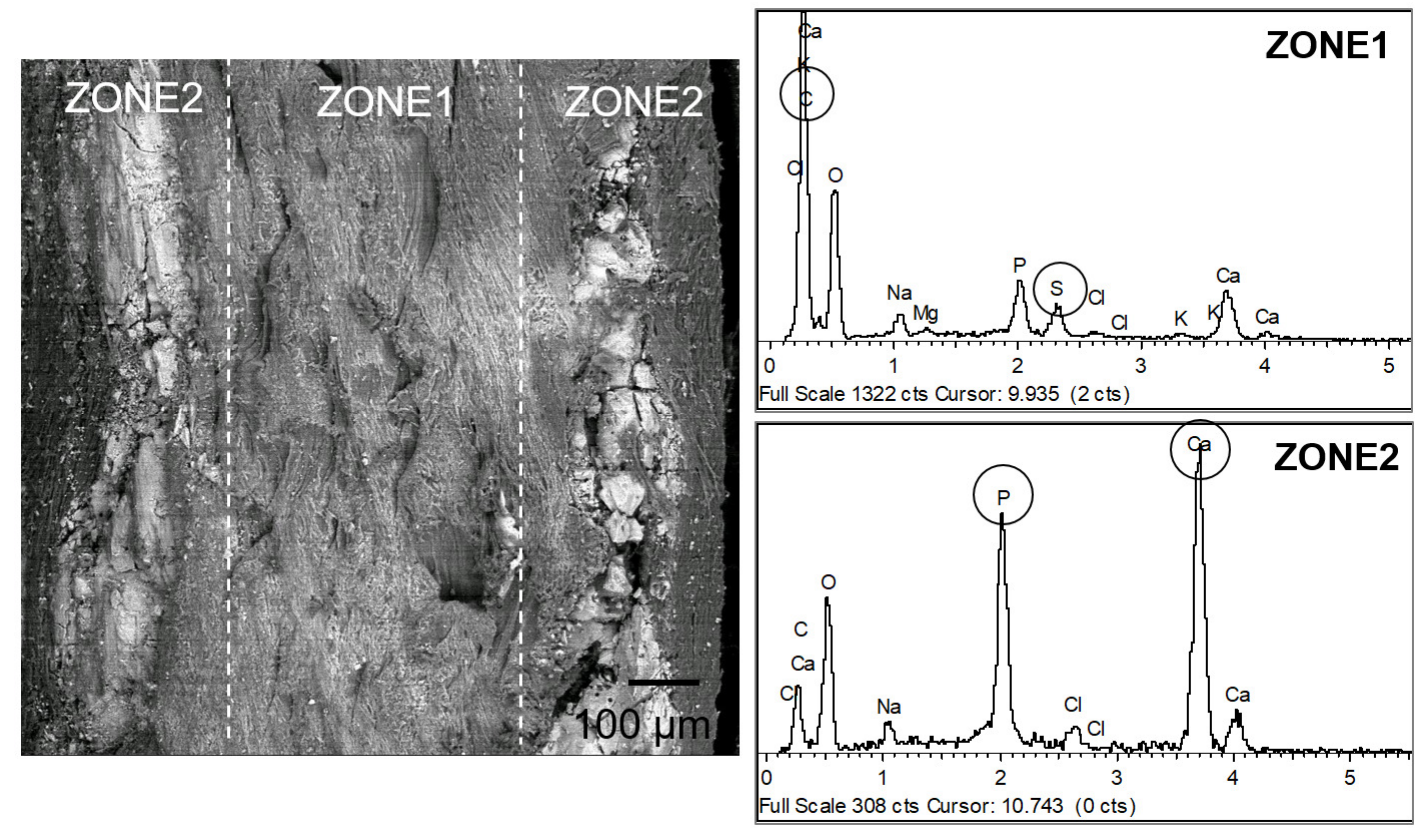

Figure 3. Electron scanning microscopy (backscattered electrons mode) of the jaw section in the sandwich type morphology where ZONE1 and ZONE2 are clearly delimited (left). EDS spectra of both zones are also presented (right).

The organic and inorganic contribution was globally quantified with the determination of moisture, organic matter and ash content for the entire crude jaws, obtaining an average ( \pm confidence interval for $\alpha=0.05$ ) of $98.04 \pm 2.12 \%, 1.48 \pm 0.22 \%$ and 0.47 $\pm 0.04 \%$ for moisture, organic matter and ashes, respectively. Dried jaws (in oven at 60 ${ }^{\circ} \mathrm{C}$ ) reached levels of $14.10 \pm 1.01 \%$ for moisture, $63.33 \pm 1.15 \%$ for organic material and $22.56 \pm 2.01 \%$ for ashes (inorganic material). Chemical composition of jaws, calculated as $\%$ of dry weight, results in $39.1 \pm 1.6 \%$ ash, $50.8 \pm 2.1 \%$ protein, $0.5 \pm$ $0.0 \%$ fat and $9.6 \pm 0.8 \%$ carbohydrates. Cartilage from other chondrichthyes fish has shown similar composition [36].

To deepen on this hybrid organic-inorganic composition, the crude unaltered jawbone was subjected to a thermal treatment $\left(950^{\circ} \mathrm{C}\right)$ to check the expected removal of the organic layers. The morphology of the original sandwich-type section after the thermal treatment is presented in Figure 4, by both scanning electron (a, b) and back scattered electron (c) microscopies. The elemental composition by EDS is also shown (d). At the 
SEM micrograph the calcined section (a) can be clearly differentiated from the adhesive of carbon, the metallic holder and the silver drop routinely used for the SEM analysis of samples. In higher magnification (b) a globular morphology of the material, typical from a calcium phosphate, can be observed. The section observed by backscattered electrons revealed a uniform composition for the material in a unique layer, in a light tone (lighter than the adhesive of carbon, the aluminum holder and the silver drop) which corresponds to heavier elements. The EDS analysis (d) confirmed the major contribution of $\mathrm{Ca}$ and $\mathrm{P}$, a higher relative intensity of $\mathrm{Na}$ and $\mathrm{Mg}$ (given the removal of the organic material), and the retention of part of sulfur. This make us to conclude that the ZONE1, with most organic material, has been removed with the thermal processing (as expected) and that certain amount of $\mathrm{S}$ from the organic material has been retained in the mineralized part, together with the $\mathrm{Na}$ and $\mathrm{Mg}$.
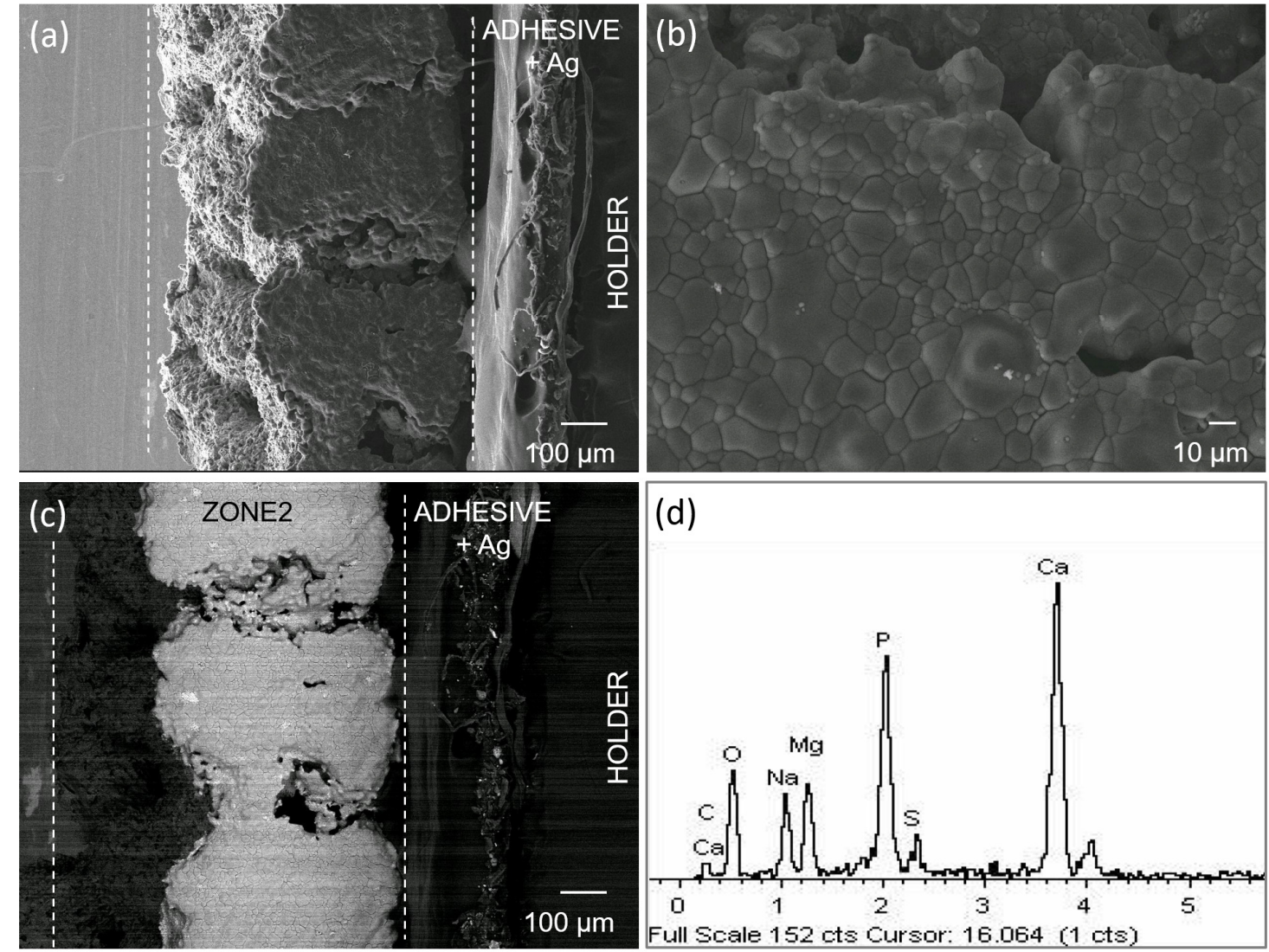

Figure 4. Electron scanning microscopy of the pyrolyzed jaw in the same sandwich type morphology section (a), in higher magnification (b), the same section using backscattered electron mode (c) and EDS spectra of the pyrolyzed sample (d).

The previous EDS spectra were reinforced, for both the crude jawbone (in ZONE1 and ZONE2) and the pyrolyzed one, by the analysis of bond configuration through FTRaman spectroscopy. Figure 5 shows the three spectra obtained, with presence of peaks 
in ZONE1 at 1663, 1450 and $1268 \mathrm{~cm}^{-1}$ attributed to the organic material-related bonds of amide I, $\mathrm{CH}_{2 \text { (def) }}$ and amide III respectively [37]. The same peaks were detected in ZONE2 but with lower intensity. The same occurred with the intense peaks at $757 \mathrm{~cm}^{-1}$ and $1003 \mathrm{~cm}^{-1}$ attributed to amino acids such as tryptophan and phenylalanine respectively [38]. The peaks at 1240, 1066, $940 \mathrm{~cm}^{-1}$ detected in ZONE1 correspond to the bonds $\mathrm{SO}_{3}{ }^{-}, \mathrm{OSO}_{3}{ }^{-}$and $\mathrm{C}-\mathrm{O}-\mathrm{C}$ of the molecule chondroitin sulfate with major prevalence of isomer 6S [24]. These peaks were not detected in ZONE2. Moreover, in ZONE2 spectrum the band of higher intensity was detected at $961 \mathrm{~cm}^{-1}$, which is the attributed to $\mathrm{PO}_{4}^{-3}$ sym stretch from hydroxyapatite. A mineral phase contribution can also be present in ZONE1 with the broad band at $940 \mathrm{~cm}^{-1}$ being designated as vibrational band at $948 \mathrm{~cm}^{-1}$ for $\mathrm{PO}_{4}^{-3}$ sym stretch of monophasic $\beta$-TCP [5]. Finally, at the thermal processed jawbone spectrum the absence of organic material-related bonds was confirmed. The intense and narrow band at $963 \mathrm{~cm}^{-1}$ confirmed the presence of $\mathrm{PO}_{4}^{-3}$ sym stretch bonds as hydroxyapatite as well as the peaks at 1079 and $1048 \mathrm{~cm}^{-1}$ for $\mathrm{PO}_{4}^{-3}$ asym stretch, 433 and $589 \mathrm{~cm}^{-1}$ for sym bending and at $613 \mathrm{~cm}^{-1}$ for asym bending [5,39].

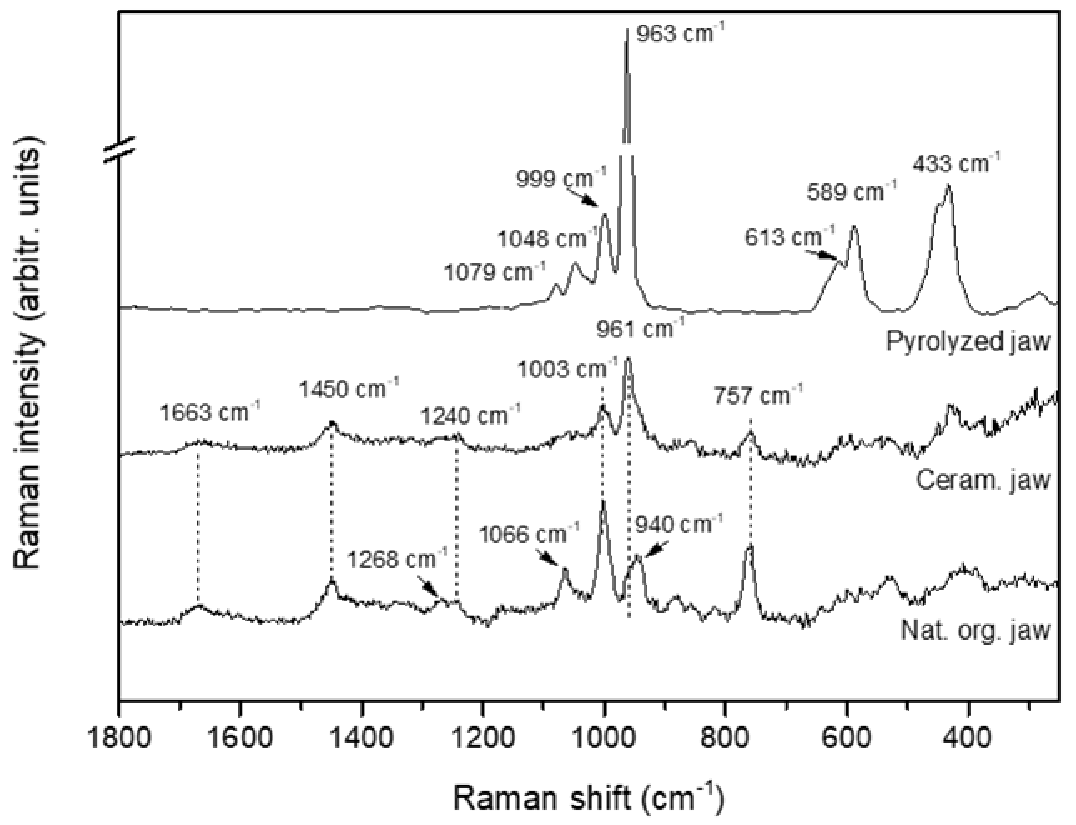

Figure 5. Raman spectra of both P. glauca jaw sandwich-type morphology layers (ZONE1, ZONE2) and the material after thermal treatment (pyrolyzed jaw).

After the descriptive structural and chemical analysis of $P$. glauca jaw, the high potential of this fishing by-product as a source of both chondroitin sulfate (CS) and 
calcium phosphate is clear. In the case of the sulfated glycosaminoglycan (GAG) the finding of a new sustainable source of this biomolecule and, moreover, appearing it with prevalence in isomer CS-C (6-sulfation) is of great interest. The obtention of CS with prevalence of 6 sulfation position in substantial yields is rare in common and sustainable sources. This isomeric form has been recently described for fish by-products such as small-spotted catshark (Scyliorhinus canicula, wholebody), blue shark (Prionace glauca, head), and ray (Raja clavata, skeleton) [23,25]. It is the first time that CS has been documented in the P. glauca jawbone, concentrated in alternating layers to the calcium phosphate ones. Its interest is related to the proved CS-based hydrogels promotion of 3D chondrogenesis [40] and the providing of biomechanical properties on numerous connective tissues such as cartilage, ligaments and tendons. In fact, and in relation to the isomeric form found at the present work, a significant negative correlation between levels of C6S and age has been described in human tissues as well as a diminished ratio of $\mathrm{C} 6 \mathrm{~S} / \mathrm{C} 4 \mathrm{~S}$ in synovial fluid and the cartilage of patients affected by osteoarthritis in advanced and terminal stages compared with early ones [24]. The obtaining of porous calcium phosphates from biological origin is also of interest for bone tissue regeneration purposes, as previously mentioned. The thermal treatment applied of $950{ }^{\circ} \mathrm{C}$ for $12 \mathrm{~h}$ was proven to be the optimal for the entire removal of organic material (Figure 5) required for the use of these ceramic materials from biological origin. Given the interest of both biomaterials, an extraction method has been applied at the present work for the obtaining of purified CS and calcium phosphate from the P. glauca jaw.

\subsection{Extraction method for purification of $\mathrm{CS}$ and $\mathrm{CaP}$}

As previously mentioned at the optimized flow diagram (Figure 1) proposed, the shark jaws were initially subjected to an enzyme hydrolysis combined with the separation by centrifugation. As result of this, a liquid enzymatic hydrolysate with high content in proteins and glycosaminoglycans, mainly CS, and a solid NHM (non-hydrolysable material) used for the extraction of calcium phosphate, were obtained. The amount of fresh NHM recovered was $26.8 \pm 2.0 \%$ (w/w of jaw), being the mineral material after washing, filtration and drying of $10.7 \pm 0.6 \%$ (w/w of jaw). This material was utilized, as substrate, for the production of CaP. The purity in CS of enzyme hydrolysates (EH) showed an average level of Ip (purity index) $=37.4 \pm 2.4 \%$. From the selective precipitation of CS by chemical treatment this parameter was increased up to Ip $=80.7$ 
$\pm 3.0 \%$. The final dried sample of CS, after membrane purification, had a chemical composition of $8.7 \pm 0.8 \%, 97.1 \pm 0.4 \%$ and $76.5 \pm 0.4 \%$ for moisture, CS purity as Ip value and CS richness, respectively. In view of these percentages, the present CS could be a potential candidate as ingredient of nutraceutical and pharma formulations for joint disease treatments and regeneration of cartilage [16]. In addition, the yields of dried CS isolated after purification steps were of $3.41 \pm 0.27 \%$ (w/wet weight jaw). This value was lower than observed for CS from small-spotted catshark $(4.8 \% \mathrm{w} / \mathrm{w}$ of wet head cartilage) and blackmouth catshark (3.7\% w/w of wet head cartilage) but higher for CS recovered from rabbit fish cartilage $[34,35,36]$. The molecular weight of CS from $P$. glauca jaw was estimated at $66.8 \mathrm{kDa}$ (number average molecular weight) with an associated polydispersity index of 1.224 . This value is similar to values previously reported for the whole head $(60 \mathrm{kDa})$ [23] [25] and in hybrid chondroitin sulfate/dermatan sulfates chain in the skin of this shark species (70 kDa) [41].

The GPC eluogram in Figure 6 shows the polymeric peak of CS at $22.03 \mathrm{~min}$ in the refractive index (RI) signal. A secondary small peak at lower elution times appears in the light scattering signals but is not visible in the RI detector. This indicates higher molecular weight species than the main CS peak at low concentration, possibly due to aggregation of CS chains. Such aggregates have been reported in other polyelectrolytes $[42,43,44]$. Composition of purified CS was initially assessed by ${ }^{1} \mathrm{H}$ NMR spectroscopy (Figure 6), with characteristic CS signals appearing between 3 and $5 \mathrm{ppm}$, except the acetyl group of GalNAc, which appears at $2.06 \mathrm{ppm}$. Additional signals typical of aliphatic (0.5-1.5ppm) and aromatic (7.0-8.5 $\mathrm{ppm})$ aminoacids are largely absent, indicating the suitability of the purification procedure to remove protein. A small quantity of keratan sulfate (KS) might remain as a contaminant in the CS sample, as evidenced by the signal at $4.71 \mathrm{ppm}$ corresponding to the anomeric carbon (H1) of Nacetyl glucosamine [45]. This possible contamination may be estimated at $1 \% \mathrm{KS}$ by comparing the intensity of this signal to that of GalNAc 4S (H4) at $4.79 \mathrm{ppm}$, based on the percentage that sulfation at position 4 of GalNAc represents of the total disaccharides. Such percentage can be calculate by relating the intensity of the signal at $4.79 \mathrm{ppm}$ to that of the acetyl group of GalNAc at 2.06-2.08 ppm [46], resulting in 7.5 $\%$ GalNAc 4S. Determination of sulfation in other positions is difficult because of signal overlap, but the information provided by NMR can be complemented by SAXHPLC after enzymatic hydrolysis. Using this method, sulfation at position 4 of GalNAc 

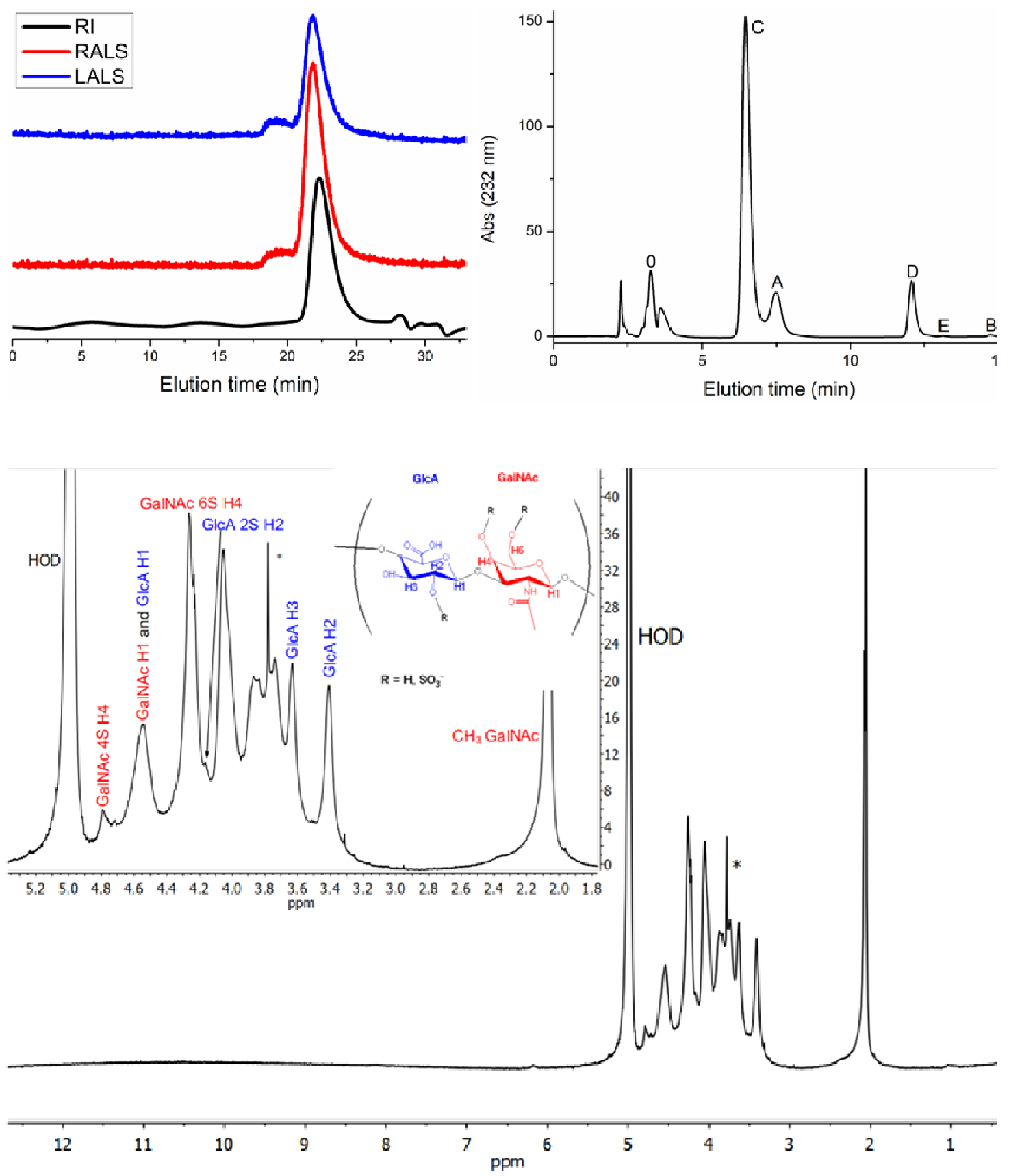

Figure 6. FT-Characterization of CS fromshark jaw. Top left: Gel Permeation Chromatography (GPC) eluograms (RALS: right angle light scattering; LALS: lowangle light scattering; RI: refractive index); Top right: SAX-HPLC chromatograms (0: $\triangle \mathrm{UA}-$ GalNAc; A: $\triangle \mathrm{UA}-\mathrm{GalNAc}(4 \mathrm{~S})$; C: $\triangle \mathrm{UA}-\mathrm{GalNAc}(6 \mathrm{~S})$; D: $\Delta \mathrm{UA}(2 \mathrm{~S})-\mathrm{GalNAc}(6 \mathrm{~S})$; E: $\Delta \mathrm{UA}-\mathrm{GalNAc}(4,6 \mathrm{~S}) ; \mathrm{B}: \Delta \mathrm{UA}(2 \mathrm{~S})-\mathrm{GalNAc}(4 \mathrm{~S}))$; Bottom: 1H NMR spectrum in $\mathrm{D} 2 \mathrm{O}$ at $10{ }^{\circ} \mathrm{C}$.

accounts for $13 \%$ of the total disaccharide units in CS, slightly higher than $7.5 \%$ estimated by NMR. This discrepancy may be partially due to the contribution to the signal at 2.06-2.08 ppm of other GAGs containing GalNAc or GlcNAc in their structures, such as KS. Besides 4S GalNAc, SAX-HPLC analysis reveals predominant 
sulfation at position 6 of GalNAc at $68 \%$, while non-sulfated disaccharides only comprise $7 \%$. Disulfated units are mainly represented by D-units (GlcA2S-GalNAc6S) at $11 \%$, as other disulfated disaccharides are only present in minute amounts (close to 1 $\%)$. The results are quite similar to those reported for CS isolated from the whole head of P. glauca (10\% CS-A, $64 \%$ CS-C, $16 \%$ CS-0, $9 \%$ CS-D). The main difference is the slightly higher percentage of sulfated units in jaw CS and about only half of the unsulfated units found in head CS [25].

In parallel to the CS purification mentioned above, thermal treatment up to $950{ }^{\circ} \mathrm{C}$ with controlled heat and cooling ramps was carried out on the solid NHM (non-hydrolysable material) sample for the purification of the mineral part. At Figure 7 the porous microstructure of pyrolyzed jawbone in cross section is showed (a-c) with porosity uniformly distributed for the entire sample (a) in a range of mean sizes of 80-150 $\mu \mathrm{m}$ and with the presence of merged pores up to $\approx 250 \mu \mathrm{m}$ in the longest axis is shown (b). A pore in detail can be observed at micrograph (c). These pore sizes are within the appropriate ranges recommended for biomedical applications LeGeres, 2002; TatayDiaz, 2008; Mour, 2010 [45,46,47] [47,48,49]. This innate porosity will be complemented with intergranular pores after the milling of the jaw. Morphology of solid NHM fraction before (d,e) and after thermal treatment $(\mathrm{f}, \mathrm{g})$ is also presented. The porosity of the solid NHM fraction was clearly observed before the thermal treatment (e) together with change in color (d) to whiter tones (f) of the fraction after thermal treatment. Finally, the EDS spectrum of crude jaw ZONE1 is included (h) together with the one of the solid NHM before (i) and after thermal treatment (j). After the removal of $\mathrm{CS}$ (i), $\mathrm{C}$ and $\mathrm{O}$ signals were detected at the same levels of $\mathrm{Ca}$ and $\mathrm{P}$ (h). As it was expected relative intensity of $\mathrm{S}$ was also diminished. Once NHM was subjected to the thermal treatment (j), the intensity of $\mathrm{C}$ detection was drastically diminished (as desired) as well as $\mathrm{O}$, this latter with lower intensity to levels of $\mathrm{Ca}$ and $\mathrm{P}$. The detection of $\mathrm{Mg}$ increases at this step as consequence of the purification process, being registered at the same level of Na. Sulfur was detected but in an intensity even lower than before the thermal treatment (i). 


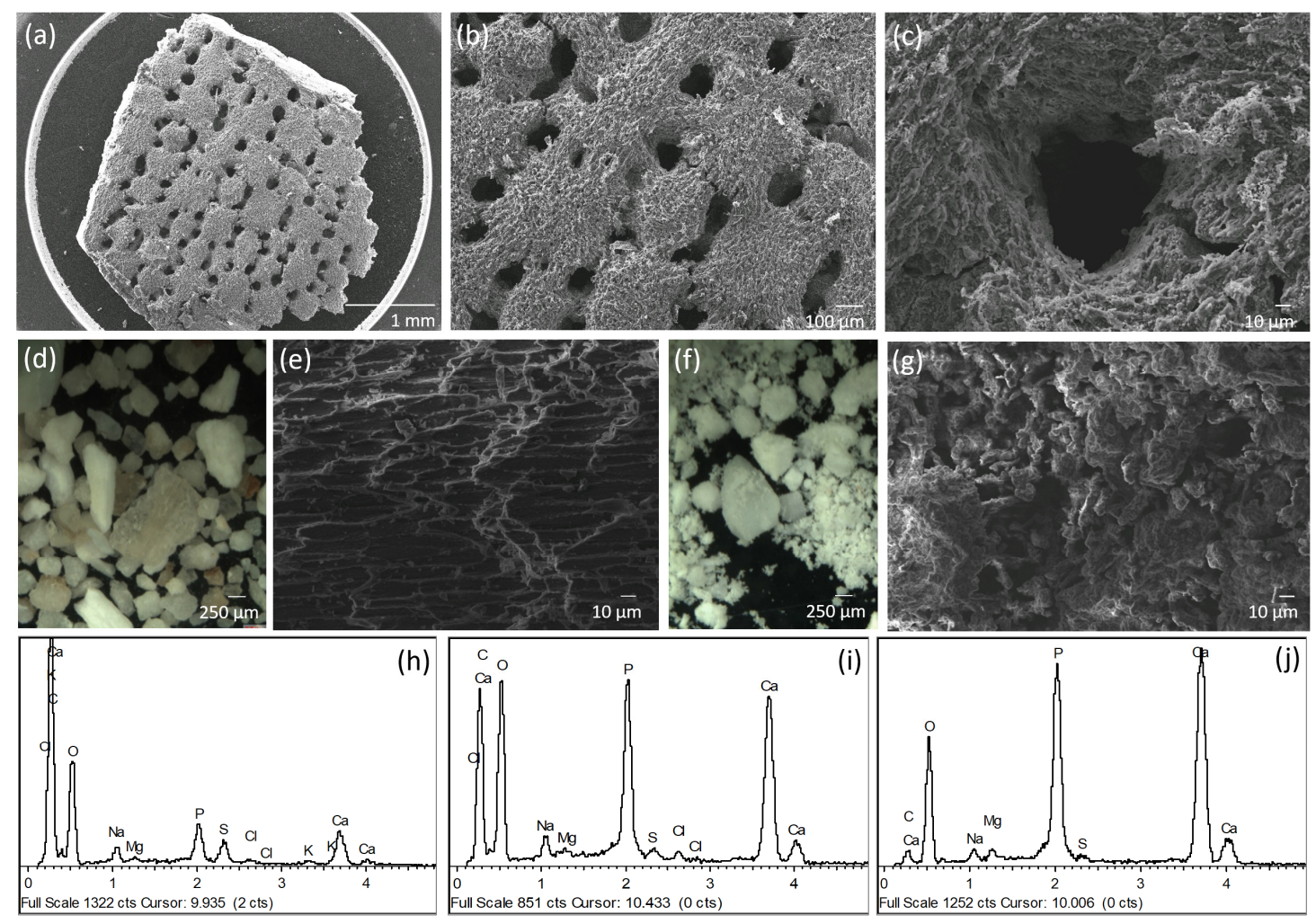

Figure 7. SEM micrographs of the pyrolyzed jawmaterial in cross section at differentmagnifications (a-c) where porosity of thematerial can be observed. Micrographs ofNHMfraction before (d, e) and after thermal treatment (f, g) are also presented together with EDS spectra of crude jaw in ZONE1 (h), NHM before (i) and after thermal treatment (j).

The bonding configuration of this purified mineral fraction was characterized by Raman spectroscopy (Figure 8), where spectrum obtained for the NHM fraction before thermal treatment is also presented. The NHM spectrum before thermal treatment validates the efficiency of the enzymatic hydrolysis for the separation of inorganic-organic phases as presence peaks at 1663,1450 and $1268 \mathrm{~cm}^{-1}$ respectively attributed to the organic material-related bonds of amide I, $\mathrm{CH}_{2(\mathrm{def})}$ and amide III were not detected or detected in an extremely low intensity together with the ones related to the amino acids such as tryptophan and phenylalanine at $757 \mathrm{~cm}^{-1}$ and $1003 \mathrm{~cm}^{-1}$ respectively, which intense peaks were detected at the CaP-based ZONE2 layer in crude jaw (Figure 5). As expected peaks at 1240, 1066 and $940 \mathrm{~cm}^{-1}$ corresponding to the bonds $\mathrm{SO}_{3}{ }^{-}, \mathrm{OSO}_{3}{ }^{-}$and C-O-C of the molecule chondroitin sulfate are also absent, and an intense peak at 963 attributed to $\mathrm{PO}_{4}^{-3}$ sym stretch $\left(v_{1}\right)$ of calcium phosphates was clearly detected. This vibration appears at the spectrum of the purified mineral fraction (P. glauca pyrolyzed CS-free jaw) in position $965 \mathrm{~cm}^{-1}$ with a shoulder in $975 \mathrm{~cm}^{-1}$ (moved from positions $961 \mathrm{~cm}^{-1}$ in crude jaw and $963 \mathrm{~cm}^{-1}$ in NHM fraction) as a very intense and sharp band. 


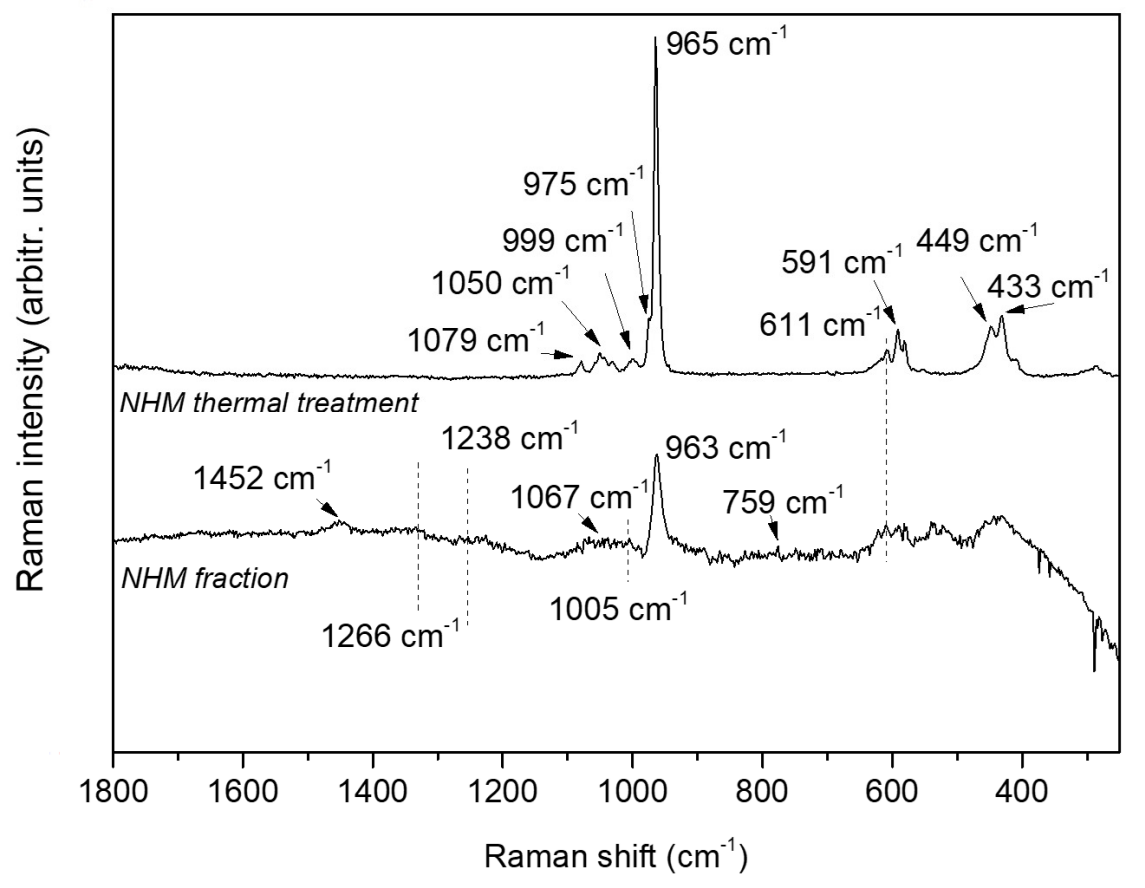

Figure 8. Raman spectra of P. glauca jaw NHM fraction before and after thermal treatment.

Going into detail within calcium phosphates, this vibration is refereed in literature Kotsoupoulos, 2002 [37][39] at $961 \mathrm{~cm}^{-1}$ for hydroxyapatite and at $970 \mathrm{~cm}^{-1}$ with a shoulder at $961 \mathrm{~cm}^{-1}$ in case of tricalcium phosphate. Other authors Aguiar,2018 [5] [5] assign the vibration $\mathrm{PO}_{4}^{-3}\left(v_{1}\right)$ at $962 \mathrm{~cm}^{-1}$ and $956 \mathrm{~cm}^{-1}$ for hydroxyapatite and $972 \mathrm{~cm}^{-}$ ${ }^{1}, 958-968 \mathrm{~cm}^{-1}$ and $948 \mathrm{~cm}^{-1}$ for $\beta$-TCP. Having into account the displacement of the band, it seems that after the enzyme hydrolysis process and the thermal treatment, the initial hydroxyapatite becomes into a biphasic material with a certain contribution of tricalcium phosphate or other variations such as whitlockite (presence of $\mathrm{Mg}$ ). The other vibrations attributed to $\mathrm{PO}_{4}{ }^{-3}$ asym stretch $\left(v_{3}\right)$ of hydroxyapatite at $1079,1050 \mathrm{~cm}^{-1}$ and $1044 \mathrm{~cm}^{-1}, \mathrm{PO}_{4}^{-3}$ bend $\left(v_{4}\right)$ at 611 and $591 \mathrm{~cm}^{-1}$ of hydroxyapatite and, finally, $\mathrm{PO}_{4}^{-3}$ bend $\left(v_{2}\right)$ of hydroxyapatite at 449 and $433 \mathrm{~cm}^{-1}$ are also detected.

The structure of the NHM fraction after thermal treatment was confirmed with XRD analysis (named as $\mathrm{CaP} 2$ ), compared to the one obtained from the direct thermal treatment of the crude jaw (avoiding the enzymatic hydrolysis for the extraction of CS, named as $\mathrm{CaP} 1$ ). Both diffraction patterns are shown in Figure 9 with peaks at $\mathrm{CaP} 2$ pattern located at positions $25.91^{\circ}, 31.86^{\circ}, 32.23^{\circ}, 33.01^{\circ}$ and $34.10^{\circ}$ characteristic of hydroxyapatite $\left[\mathrm{Ca}_{5}\left(\mathrm{PO}_{4}\right)_{3}(\mathrm{OH})\right]$ corresponding to the diffraction planes $(0,0,2)$, 
(a)

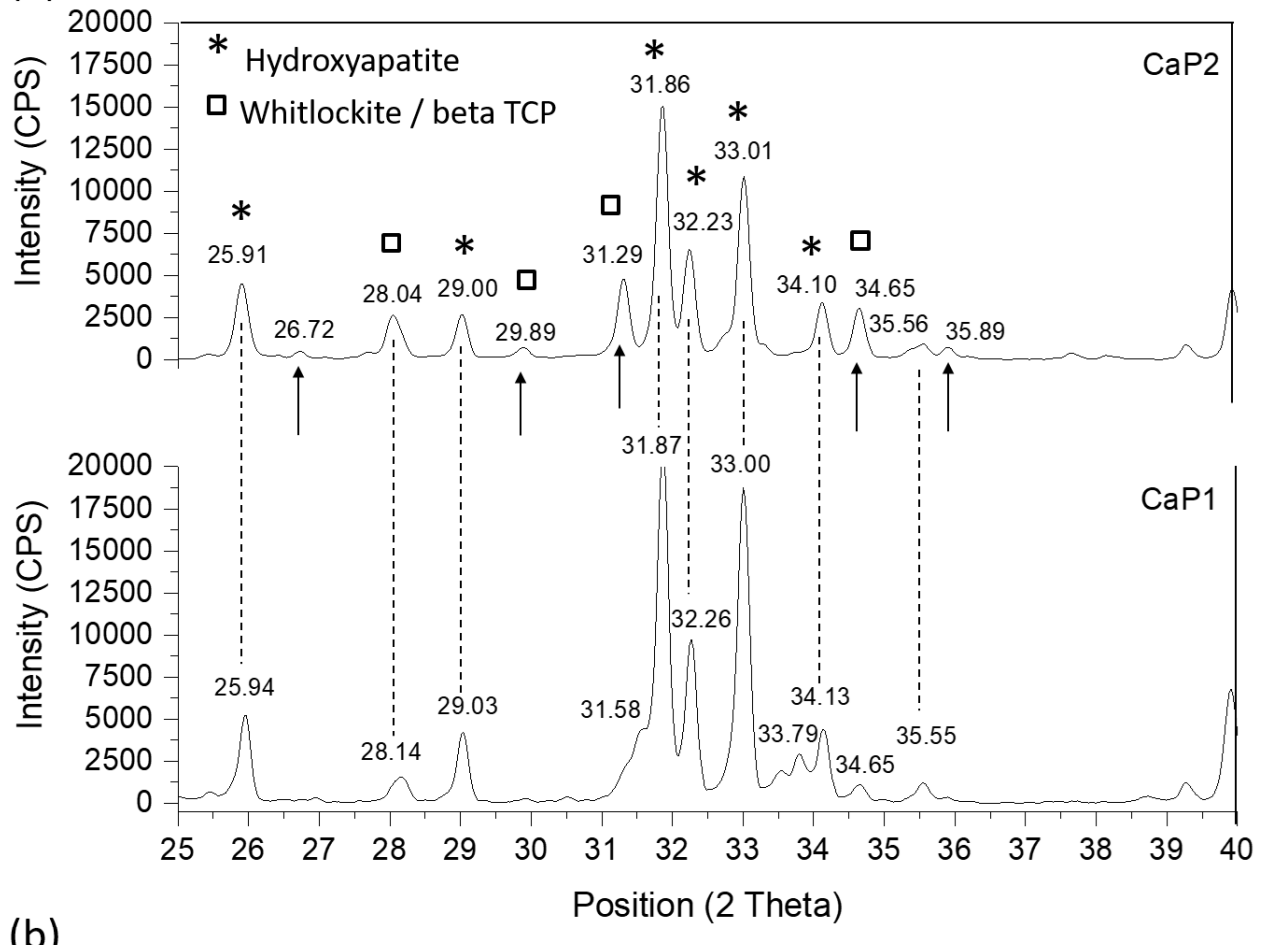

(b)

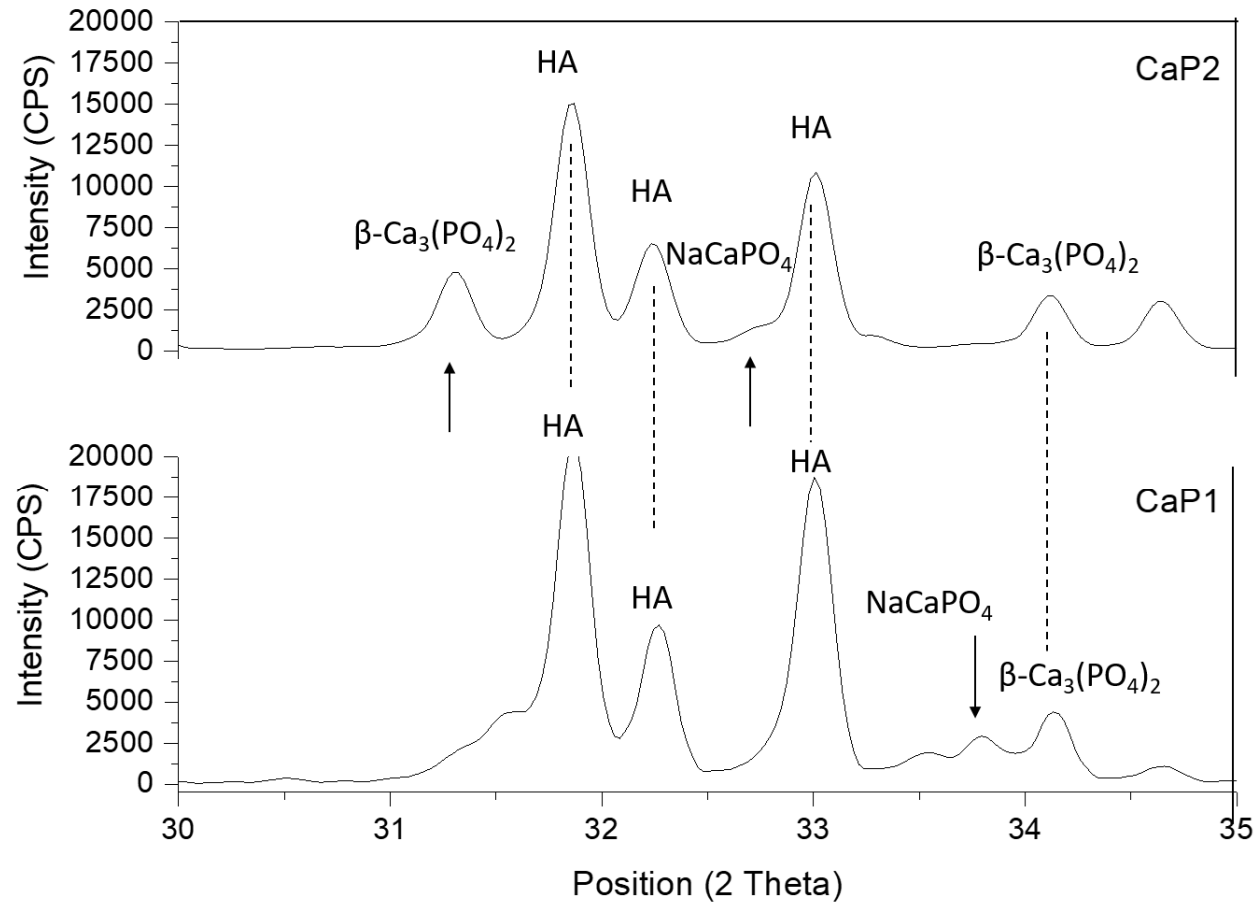

Figure 8. Raman XRD patterns of NHM fraction after thermal treatment $(\mathrm{CaP} 2)$ and of the directly pyrolyzed jaw (CaP1) in the range of positions between $25^{\circ}$ and $40^{\circ}$ (a). The same diffraction patterns are amplified below in positions range between $30^{\circ}$ and $35^{\circ}$ to indicate diffractions attributed to $\mathrm{NaCaPO} 4$ (b). 
$(1,2,1),(1,1,2),(3,0,0)$ and $(2,0,2)$ (5Aguiar et al 2018) and a contribution of $\beta$-TCP $\left(\mathrm{Ca}_{3} \mathrm{O}_{8} \mathrm{P}_{2}\right)$ or other similar structures (isomorphisms) such as whitlockite $\left[\mathrm{Ca} 9 \mathrm{Mg}\left(\mathrm{PO}_{3} \mathrm{OH}\right)\left(\mathrm{PO}_{4}\right)_{6}\right]$, given the presence of $\mathrm{Mg}$ in the mineral composition as shown in EDS spectrum at Figure 7(j), at positions 28.04, 31.29 and 34.65 attributed to crystal planes $(2,1,4)(0,2,10)$ and $(2,2,0)$ respectively Aguiar, 2018; Tabares, 2013 [5, 48] [5,50]. XRD semi-quantitative estimation attributed the composition of $\mathrm{CaP} 2$ for HA in around a $60 \%$ and whitlockite / $\beta$-TCP in around a $40 \%$. Diffraction peaks of $\mathrm{CaP} 1$ pattern were mainly detected in typical positions $\left(25.94^{\circ}, 31.87^{\circ}, 32.26^{\circ}, 33.00^{\circ}\right.$, $\left.34.13^{\circ}\right)$ for crystal planes of hexagonal hydroxyapatite $((0,0,2),(1,2,1),(1,1,2),(3,0,0)$ and $(2,0,2)$ respectively) (JCPDS No. 09-0432). A slight contribution of whitlockite/ $\beta$ TCP was also detected at position $28.14^{\circ}$ and $34.65^{\circ}$ respectively attributed to the planes $(2,1,4)$ and $(2,2,0)$. Potential small contribution of $\mathrm{Na}$ as $\mathrm{NaCaPO}_{4}$ (rhenanite) can be observed in both amplified patterns (Figure 9b) in the range of positions from 30 ${ }^{\circ}$ to $35^{\circ}$, which comes from the incorporation of $\mathrm{Na}+$ in the HA Hung, 2012 [53] [51]. At this case the XRD semi-quantitative estimation mainly attributed the composition to HA (around an $85 \%$ ).

Therefore, as for CS, the mineral phase has been purified in the form of biphasic calcium phosphate of HA and $\beta$-TCP / whitlockite. The contribution of $\beta$-TCP / whitlockite increases when the crude jaw is previously subjected to an enzymatic hydrolysis, this process causes changes in the material that are reflected at a structural level after the heat treatment. In addition, the presence of sulfur in the mineral fraction directly obtained from the thermal treatment on the crude jaw and the presence of sodium and magnesium in both mineral fractions (essential elements with role in bone metabolism) were also proven, being the latter incorporated into the crystalline network as whitlockite. A range in the mineral fractions can be then obtained to cover clinical requirements of highly stable calcium phosphates (mostly based on HA) or others where the bioceramic must provide a certain degree of resorbability (relevant presence of $\beta$ TCP/whitlockite) Tataya-Diaz, 2008;Fernandez-Heranadez, 2017; Giannoudis, 2005; Chiarello, 2005; Cook, 2009 [48,51,52,53,54] [48,52,53,54,55].

\section{Conclusions}

Crude blue shark jawbone was revealed to be organized in a sandwich-type structure in cross section based on alternate layers. These layers presented different compositions 
with ones enriched in content of $\mathrm{Ca}$ and $\mathrm{P}$ with presence of $\mathrm{C}$ against the others with prevalence in $\mathrm{C}$ content, relevant presence of $\mathrm{S}$ and low contribution of $\mathrm{Ca}$ and $\mathrm{P}$. In both alternate layers the presence of $\mathrm{O}$ was quantified (as it forms part of both organic and inorganic contributions) as well as $\mathrm{Mg}$ in trace quantities and marine salts ( $\mathrm{Na}$ and $\mathrm{Cl})$. The inner cavity of the sandwich-type structure was also observed to act as the reservoir for new dental pieces. FT-Raman spectroscopy confirmed the elemental analysis with the most intense band detected at $961 \mathrm{~cm}^{-1}$ attributed to $\mathrm{PO}_{4}{ }^{-3}$ sym stretch from hydroxyapatite $\left[\mathrm{Ca}_{5}\left(\mathrm{PO}_{4}\right)_{3}(\mathrm{OH})\right]$ in the mineralized layers (inorganic material globally quantified in a $23 \pm 2 \%$ in dried jaw) and more intense bands attributed to the organic material-related bonds at the organic layers (63 $\pm 1 \%$ in dried jaw), with peaks at 1663,1450 and $1268 \mathrm{~cm}^{-1}$ assigned to amide $\mathrm{I}, \mathrm{CH}_{2(\mathrm{def})}$ and amide III respectively, and at 757 and $1003 \mathrm{~cm}^{-1}$ attributed to amino acids such as tryptophan and phenylalanine respectively. Moreover, at the organic layer specific peaks (absent at the mineral one) were detected at 1240,1066, $940 \mathrm{~cm}^{-1}$ attributed to the bonds $\mathrm{SO}_{3}{ }^{-}, \mathrm{OSO}_{3}{ }^{-}$ and $\mathrm{C}-\mathrm{O}-\mathrm{C}$ of the molecule chondroitin sulfate with major prevalence of isomer $6 \mathrm{~S}$. The integral valorization of both the hydroxyapatite and the chondroitin sulfate, is proposed at the present work and a recovery and purification process was applied in sequential steps combining enzymatic proteolysis, chemical precipitation and membrane purification, together with controlled thermal treatment at $950{ }^{\circ} \mathrm{C}$ for hydroxyapatite purification. A purified biphasic (60:40) porous calcium phosphate with characteristic diffraction peaks of hydroxyapatite and of $\beta$-TCP $\left(\mathrm{Ca}_{3} \mathrm{O}_{8} \mathrm{P}_{2}\right)$ / whitlockite $\left[\mathrm{Ca}_{9} \mathrm{Mg}\left(\mathrm{PO}_{3} \mathrm{OH}\right)\left(\mathrm{PO}_{4}\right)_{6}\right]$ was confirmed. A purified chondroitin sulfate with $\mathrm{CS}$ purity as Ip value of $97.10 \pm 0.39 \%$ and CS richness of $76.5 \pm 0.39 \%$, molecular weight of 67 $\mathrm{kDa}$ and predominant $(68 \%)$ sulfation in position 6 of GalNAc was also confirmed. The required enzymatic hydrolysis combined with the separation by centrifugation was proven to promote changes in the crude mineral fraction that were reflected at a structural level after the thermal treatment. In fact, crude jaw directly subjected to the thermal treatment (avoiding the CS recovery) revealed a calcium phosphate with main contribution of hydroxyapatite $(85 \%)$ and much lower of $\beta$-TCP/whitlockite. This finding opens the range in the mineral compositions that can be provided, from highly stable (HA) to resorbable calcium phosphates (relevant presence of $\beta$-TCP/whitlockite). On the other hand, the properties of the purified CS obtained situate it as a potential ingredient of nutraceutical and pharma formulations for joint disease treatments. 


\section{Conflict of interest}

The authors declare no conflict of interest.

\section{Acknowledgements}

This research was partially supported by the European Union projects 0245_IBEROS_1_E and 0302_CVMAR_I_1_P, both from Interreg (POCTEP 2015) and BLUEHUMAN EAPA_151/2016 from INTERREG Atlantic Area, European Regional Development Fund. Moreover, regional funds for Competitive Reference Groups (GRC) ED431C 2017_51, Research networks ED431D 2017/13 and Groups of Potential Growth, all of them from Xunta de Galicia (Spain), are also acknowledged. M. López Álvarez and J. Valcárcel thank funding support provided by 0245_IBEROS_1_E from EU Interreg (POCTEP) project. Technical support by CACTI (University of Vigo) is also gratefully acknowledged.

\section{References}

[1] C. Grosso, P. Valentão, F. Ferreres, P.B. Andrade, Bioactive Marine Drugs and Marine Biomaterials for Brain Diseases, Marine Drugs 12(5) (2014) 2539. https://doi:10.3390/md12052539.

[2] J. Venkatesan, S.-K. Kim, Marine Biomaterials, in: S.-K. Kim (Ed.), Springer Handbook of Marine Biotechnology, Springer Berlin Heidelberg, Berlin, Heidelberg, 2015, pp. 1195-1215 https://doi.org/10.1007/978-3-642-53971-8.

[3] C. Zhang, X. Li, S.-k. Kim, Application of marine biomaterials for nutraceuticals and functional foods, Food Science and Biotechnology 21(3) (2012) 625-631. https://doi.org/10.1007/s10068-012-0081-6.

[4] J.A. Vázquez, M. Blanco, J. Fraguas, L. Pastrana, R. Pérez-Martín, Optimisation of the extraction and purification of chondroitin sulphate from head by-products of Prionace glauca by environmental friendly processes, Food Chemistry 198 (2016) 28-35. http://dx.doi.org/10.1016/j.foodchem.2015.10.087.

[5] H. Aguiar, S. Chiussi, M. López-Álvarez, P. González, J. Serra, Structural characterization of bioceramics and mineralized tissues based on Raman and XRD techniques, Ceramics International 44(1) (2018) 495-504. https://doi.org/10.1016/j.ceramint.2017.09.203.

[6] S.V. Dorozhkin, Calcium orthophosphate cements and concretes, Materials 2(1) (2009) 221291. https://doi.org/10.3390/ma2010221.

[7] M. López-Álvarez, S. Pérez-Davila, C. Rodríguez-Valencia, P. González, J. Serra, The improved biological response of shark tooth bioapatites in a comparativein vitrostudy with synthetic and bovine bone grafts, Biomedical Materials 11(3) (2016) 035011. https://doi.org/10.1088/1748-6041/11/3/035011.

[8] B. Leon, J.A. Jansen, Thin calcium phosphate coatings for medical implants, SpringerVerlag, New York, 2009, https://doi.org/10.1007/978-0-387-77718-4.

[9] M. Boutinguiza, J. Pou, R. Comesaña, F. Lusquiños, A. de Carlos, B. León, Biological hydroxyapatite obtained from fish bones, Materials Science and Engineering: C 32(3) (2012) 478-486. https://doi.org/10.1016/j.msec.2011.11.021.

[10] M.P. Ferraz, F.J. Monteiro, C.M. Manuel, Hydroxyapatite Nanoparticles: A Review of Preparation Methodologies, Journal of Applied Biomaterials and Biomechanics 2(2) (2004) 7480. https://doi.org/10.1177/228080000400200202. 
[11] W. Linhart, F. Peters, W. Lehmann, K. Schwarz, A.F. Schilling, M. Amling, J.M. Rueger, M. Epple, Biologically and chemically optimized composites of carbonated apatite and polyglycolide as bone substitution materials, Journal of Biomedical Materials Research 54(2) (2001) 162-171. https://doi.org/10.1002/1097-4636(200102).

[12] S.M. Best, A.E. Porter, E.S. Thian, J. Huang, Bioceramics: Past, present and for the future, Journal of the European Ceramic Society 28(7) (2008) 1319-1327. https://doi.org/10.1016/j.jeurceramsoc.2007.12.001.

[13] H.M. Kim, Y. Kim, S.J. Park, C. Rey, L. HyunMi, M.J. Glimcher, J. Seung Ko, Thin film of low-crystalline calcium phosphate apatite formed at low temperature, Biomaterials 21(11) (2000) 1129-1134. https://doi.org/10.1016/S0142-9612(99)00265-3.

[14] T. Leventouri, Synthetic and biological hydroxyapatites: Crystal structure questions, Biomaterials 27(18) (2006) 3339-3342. https://doi.org/10.1016/j.biomaterials.2006.02.021.

[15] C. Malavaki, S. Mizumoto, N. Karamanos, K. Sugahara, Recent Advances in the Structural Study of Functional Chondroitin Sulfate and Dermatan Sulfate in Health and Disease, $\begin{array}{lllll}\text { Connective } & \text { Tissue } & \text { Research } & \text { 49(3-4) } & \text { (2008) }\end{array}$ https://doi.org/10.1080/03008200802148546.

[16] J. Valcarcel, R. Novoa-Carballal, R.I. Pérez-Martín, R.L. Reis, J.A. Vázquez, Glycosaminoglycans from marine sources as therapeutic agents, Biotechnology Advances 35(6) (2017) 711-725. https://doi.org/10.1016/j.biotechadv.2017.07.008.

[17] J.Y. Reginster, J. Dudler, T. Blicharski, K. Pavelka, Pharmaceutical-grade Chondroitin sulfate is as effective as celecoxib and superior to placebo in symptomatic knee osteoarthritis: the ChONdroitin versus CElecoxib versus Placebo Trial (CONCEPT), Annals of the Rheumatic Diseases 76(9) (2017) 1537. https://doi.org/10.1136/annrheumdis-2016-210860.

[18] J. Martel-Pelletier, A. Farran, E. Montell, J. Vergés, J.-P. Pelletier, Discrepancies in composition and biological effects of different formulations of chondroitin sulfate, Molecules 20(3) (2015) 4277-4289. https://doi.org/10.3390/molecules20034277.

[19] N. Celikkin, C. Rinoldi, M. Costantini, M. Trombetta, A. Rainer, W. Święszkowski, Naturally derived proteins and glycosaminoglycan scaffolds for tissue engineering applications, Materials Science and Engineering: C 78 (2017) 1277-1299. https://doi.org/10.1016/j.msec.2017.04.016.

[20] R. Benito-Arenas, E. Doncel-Pérez, M. Fernández-Gutiérrez, L. Garrido, E. GarcíaJunceda, J. Revuelta, A. Bastida, A. Fernández-Mayoralas, A holistic approach to unravelling chondroitin sulfation: Correlations between surface charge, structure and binding to growth $\begin{array}{lllll}\text { factors, } & \text { Carbohydrate } & \text { Polymers } & 202 & \text { (2018) }\end{array}$ https://doi.org/10.1016/j.carbpol.2018.08.120.

[21] D. Soares da Costa, R.L. Reis, I. Pashkuleva, Sulfation of Glycosaminoglycans and Its Implications in Human Health and Disorders, Annual Review of Biomedical Engineering 19(1) (2017) https://doi.org/10.1146/annurev-bioeng-071516-044610.

[22] K. Arima, H. Fujita, R. Toita, A. Imazu-Okada, N. Tsutsumishita-Nakai, N. Takeda, Y. Nakao, H. Wang, M. Kawano, K. Matsushita, H. Tanaka, S. Morimoto, A. Nakamura, M. Kitagaki, Y. Hieda, R. Hatto, A. Watanabe, T. Yumura, T. Okuhara, H. Hayashi, K. Shimizu, K. Nakayama, S. Masuda, Y. Ishihara, S. Yoshioka, S. Yoshioka, S. Shirade, J.-i. Tamura, Amounts and compositional analysis of glycosaminoglycans in the tissue of fish, Carbohydrate Research 366 (2013) 25-32. https://doi.org/10.1016/j.carres.2012.11.010.

[23] N. Takeda, S. Horai, J.i. Tamura, Facile analysis of contents and compositions of the chondroitin sulfate/dermatan sulfate hybrid chain in shark and ray tissues, Carbohydrate Research 424 (2016) 54-58. https://doi.org/10.1016/j.carres.2016.02.006.

[24] M. López-Álvarez, E. López-Senra, J. Valcárcel, J.A. Vázquez, J. Serra, P. González, Quantitative evaluation of sulfation position prevalence in chondroitin sulphate by Raman spectroscopy, Journal of Raman Spectroscopy 50(5) (2019) 656-664. https://doi.org/10.1002/jrs.5563.

[25] R. Novoa-Carballal, R. Pérez-Martín, M. Blanco, C.G. Sotelo, D. Fassini, C. Nunes, M.A. Coimbra, T.H. Silva, R.L. Reis, J.A. Vázquez, By-products of Scyliorhinus canicula, Prionace glauca and Raja clavata: A valuable source of predominantly $6 \mathrm{~S}$ sulfated chondroitin sulfate, Carbohydrate Polymers 157 (2017) 31-37. http://dx.doi.org/10.1016/j.carbpol.2016.09.050. 
[26] G.S. Diogo, E.L. Senra, R.P. Pirraco, R.F. Canadas, E.M. Fernandes, J. Serra, R.I. PérezMartín, C.G. Sotelo, A.P. Marques, P. González, J. Moreira-Silva, T.H. Silva, R.L. Reis, Marine Collagen/Apatite Composite Scaffolds Envisaging Hard Tissue Applications, Marine Drugs 16(8) (2018) 269. https://doi.org/10.3390/md16080269.

[27] M. López-Álvarez, E. Vigo, C. Rodríguez-Valencia, V. Outeiriño-Iglesias, P. González, J. Serra, In vivo evaluation of shark teeth-derived bioapatites, Clinical Oral Implants Research 28(9) (2017) e91-e100. https://doi.org/10.1111/clr.12934.

[28] B. Iñarra, C. Bald, M. Cebrián, L.T.Antelo, A. Franco-Uría, J.A. Vázquez, R.I. PérezMartín, J. Zufía, The European Landing Obligation: Reducing Discards in Complex, MultiSpecies and Multi-Jurisdictional Fisheries, Chapter 17, Springer, 2019, https://doi.org/10.1007/978-3-030-03308-8.

[29] AOAC, Association of Official Analytical Chemistry. Methods of Analysis., Washington DC, USA, 1997.

[30] M. Dubois, K.A. Gilles, J.K. Hamilton, P.A. Rebers, F. Smith, Colorimetric method for determination of sugars and related substances, Analytical Chemistry 28 (1956) https://doi.org/10.1021/ac60111a017.

[31] O.H. Lowry, N.J. Rosebrough, A.L. Farr, R.J. Randall, Protein measurement with the Folin phenol reagent, Journal of Biological Chemistry 193(1) (1951) 265-275.

[32] B.M. van den Hoogen, P.R. van Weeren, M. Lopes-Cardozo, L.M. van Golde, A. Barneveld, C.H. van de Lest, A microtiter plate assay for the determination of uronic acids, Analytical Biochemistry 257(2) (1998) 107-111. https://doi.org/10.1006/abio.1997.2538.

[33] M.A. Murado, J. Fraguas, M.I. Montemayor, J.A. Vázquez, P. González, Preparation of highly purified chondroitin sulphate from skate (Raja clavata) cartilage by-products. Process optimization including a new procedure of alkaline hydroalcoholic hydrolysis, Biochemical Engineering Journal 49(1) (2010) 126-132. http://dx.doi.org/10.1016/j.bej.2009.12.006.

[34] J.A. Vázquez, J. Fraguas, R. Novoa-Carballal, R.L. Reis, R.I. Pérez-Martín, J. Valcarcel, Optimal isolation and characterisation of chondroitin sulfate from rabbit fish (Chimaera monstrosa), $\quad$ Carbohydrate $\quad$ Polymers $210 \quad$ (2019) 302-313. https://doi.org/10.1016/j.carbpol.2019.01.075.

[35] J.A. Vázquez, J. Fraguas, R. Novoa-Carvallal, R. Reis, L. Antelo, R. Pérez-Martín, J. Valcarcel, Isolation and chemical characterization of chondroitin sulfate from cartilage byproducts of Blackmouth Catshark (Galeus melastomus), Marine Drugs 16(10) (2018) 344. https://doi.org/10.3390/md16100344.

[36] M. Blanco, J. Fraguas, C.G. Sotelo, R.I. Pérez-Martín, J.A. Vázquez, Production of chondroitin sulphate from head, skeleton and fins of Scyliorhinus canicula by-products by combination of enzymatic, chemical precipitation and ultrafiltration methodologies, Marine Drugs 13(6) (2015) 3287-3308. http://dx.doi.org/10.3390/md13063287.

[37] R. Valdés, S. Stefanov, S. Chiussi, M. López-Alvarez, P. González, Pilot research on the evaluation and detection of head and neck squamous cell carcinoma by Raman spectroscopy, Journal of Raman Spectroscopy 45(7) (2014) 550-557. https://doi.org/10.1002/jrs.4498.

[38] P.T. Freire, F.M. Barboza, J.A. Lima, F.E. Melo, J. Mendes Filho, Raman Spectroscopy of Amino Acid Crystals, Raman Spectroscopy and Applications (2017) https://doi.org/105772/65480.

[39] S. Koutsopoulos, Synthesis and characterization of hydroxyapatite crystals: A review study on the analytical methods, Journal of Biomedical Materials Research 62(4) (2002) 600-612. https://doi.org/10.1002/jbm.10280.

[40] S. Varghese, N.S. Hwang, A.C. Canver, P. Theprungsirikul, D.W. Lin, J. Elisseeff, Chondroitin sulfate based niches for chondrogenic differentiation of mesenchymal stem cells, Matrix Biology 27(1) (2008) 12-21. https://doi.org/10.1016/j.matbio.2007.07.002.

[41] C.D. Nandini, N. Itoh, K. Sugahara, Novel 70-kDa Chondroitin Sulfate/Dermatan Sulfate Hybrid Chains with a Unique Heterogenous Sulfation Pattern from Shark Skin, Which Exhibit Neuritogenic Activity and Binding Activities for Growth Factors and Neurotrophic Factors, Journal of Biological Chemistry 280(6) (2005) 4058-4069. http://dx.doi.org/10.1074/jbc.M412074200. 
[42] S. Bertini, A. Bisio, G. Torri, D. Bensi, M. Terbojevich, Molecular weight determination of heparin and dermatan sulfate by size exclusion chromatography with a triple detector array, Biomacromolecules 6(1) (2005) 168-173. https://doi.org/10.1021/bm049693s.

[43] G. Lamarque, J.-m. Lucas, C. Viton, A. Domard, Physicochemical behavior of homogeneous series of acetylated chitosans in aqueous solution: role of various structural parameters, Biomacromolecules 6(1) (2005) 131-142. https://doi.org/10.1021/bm0496357.

[44] M.H. Ottøy, K.M. Vårum, B.E. Christensen, M.W. Anthonsen, O. Smidsrød, Preparative and analytical size-exclusion chromatography of chitosans, Carbohydrate Polymers 31(4) (1996) 253-261. https://doi.org/10.1016/S0144-8617(96)00096-3.

[45] V.H. Pomin, NMR chemical shifts in structural biology of glycosaminoglycans, Analytical Chemistry 86(1) (2013) 65-94. https://doi.org/10.1021/ac401791h.

[46] A. Mucci, L. Schenetti, N. Volpi, $1 \mathrm{H}$ and $13 \mathrm{C}$ nuclear magnetic resonance identification and characterization of components of chondroitin sulfates of various origin, Carbohydrate Polymers 41(1) (2000) 37-45. https://doi.org/10.1016/S0144-8617(99)00075-2.

[47] R.Z. LeGeros, Properties of osteoconductive biomaterials: calcium phosphates, Clinical Orthopaedics and Related Research 395 (2002) 81-98. https://doi.org/10.1097/00003086200202000-00009.

[48] A. Tatay Díaz, J.M. Pérez Sánchez, J. Ribera Zabalbeascoa, J.A. Cordero Fernández, M. Mella Sousa, Sustitutos óseos, Revista de la Sociedad Andaluza de Traumatología y Ortopedia 26(1) (2008) 2-13.

[49] M. Mour, D. Das, T. Winkler, E. Hoenig, G. Mielke, M.M. Morlock, A.F. Schilling, Advances in porous biomaterials for dental and orthopaedic applications, Materials 3(5) (2010) 2947-2974. https://doi.org/10.3390/ma3052947.

[50] D.S. Tavares, L.d.O. Castro, G.D.d.A. Soares, G.G. Alves, J.M. Granjeiro, Synthesis and cytotoxicity evaluation of granular magnesium substituted $\beta$-tricalcium phosphate, Journal of Applied Oral Science 21(1) (2013) 37-42. https://doi.org/10.1590/1678-7757201302138.

[51] I.M. Hung, W.J. Shih, M.H. Hon, M.C. Wang, The Properties of Sintered Calcium Phosphate with $[\mathrm{Ca}] /[\mathrm{P}]=1.50$, International journal of molecular sciences 13(10) (2012) 13569-13586. https://doi.org/10.3390/ijms131013569.

[52] O. Fernández-Hernández, Sustitutivos óseos, Monografías de Actualización de la Sociedad Española de Medicina y Cirugía del Pie y Tobillo 9 (2017) 45-53. https://doi.org/10.24129/j.mact.0901.fs1705007.

[53] P.V. Giannoudis, H. Dinopoulos, E. Tsiridis, Bone substitutes: An update, Injury 36(3, Supplement) (2005) S20-S27. https://doi.org/10.1016/j.injury.2005.07.029.

[54] E. Chiarello, M. Cadossi, G. Tedesco, P. Capra, C. Calamelli, A. Shehu, S. Giannini, Autograft, allograft and bone substitutes in reconstructive orthopedic surgery, Aging Clinical and Experimental Research 25(1) (2013) 101-103. https://doi.org/10.1007/s40520-013-0088-8.

[55] E.A. Cook, J.J. Cook, Bone Graft Substitutes and Allografts for Reconstruction of the Foot and Ankle, Clinics in Podiatric Medicine and Surgery 26(4) (2009) 589-605. https://doi.org/10.1016/j.cpm.2009.07.003. 